Article

\title{
Sensitivity of the Nonsubsidized Consumption Promotion Mechanisms of New Energy Vehicles to Potential Consumers' Purchase Intention
}

\author{
Yuqing Lin ${ }^{1}$, Jingjing $\mathrm{Wu}^{2, *}$ and Yongqing Xiong ${ }^{1}$ \\ 1 School of Business, Central South University, Changsha 410083, China; linyuqing@csu.edu.cn (Y.L.); \\ xyq@csu.edu.cn (Y.X.) \\ 2 School of Automotive Engineering, Hunan Communication Polytechnic, Changsha 410132, China \\ * Correspondence: wujingjing@stu.csust.edu.cn
}

Citation: Lin, Y.; Wu, J.; Xiong, Y

Sensitivity of the Nonsubsidized

Consumption Promotion

Mechanisms of New Energy Vehicles to Potential Consumers' Purchase

Intention. Sustainability 2021, 13, 4293

https://doi.org/10.3390/su13084293

Academic Editor: Jack Barkenbus

Received: 4 March 2021

Accepted: 2 April 2021

Published: 13 April 2021

Publisher's Note: MDPI stays neutral with regard to jurisdictional claims in published maps and institutional affiliations.

Copyright: (c) 2021 by the authors. Licensee MDPI, Basel, Switzerland. This article is an open access article distributed under the terms and conditions of the Creative Commons Attribution (CC BY) license (https:// creativecommons.org/licenses/by/ $4.0 /)$.

\begin{abstract}
With the background of China's new energy vehicles (NEVs) subsidies declining, there is an important practical significance to effectively play the role of the nonsubsidized consumption promotion mechanisms. The nonsubsidized mechanisms for NEVs are classified into two typesconcept induction and policy incentives, and differences in the sensitivity of the two types of mechanisms on potential consumer purchase intentions due to differences in urban traffic patterns and consumer education levels are analyzed. The results show that consumers in cities with medium to high traffic pressure are more sensitive to the right-of-way privileges component of the policy incentives, and consumers in cities with low traffic pressure are more sensitive to the charging guarantee component of the policy incentives. Consumers with medium to high education are more sensitive to the pro-environmental component in concept induction, and consumers with low education are more sensitive to the charging guarantee policy component of the policy incentives. Therefore, the implementation of the nonsubsidized mechanisms for NEVs in China should adopt differentiated strategies based on local conditions and vary with each individual.
\end{abstract}

Keywords: new energy vehicles; nonsubsidized mechanism; concept induction; policy incentives

\section{Introduction}

As environmental pollution and energy bottlenecks have become increasingly prominent, the promotion of new energy vehicles (NEVs) is an important measure to promote energy conservation and emission reduction, promote economic growth and transform industrial structure [1]. (NEVs refer to vehicles with new technologies, new structures and advanced technical principles that adopt unconventional vehicle fuels as power sources, with specific manifestations regarding (battery electric vehicles (BEVs), plug-in hybrid electric vehicles (PHEVs) and fuel cell electric vehicles (FCEV) automotive industry patterns). In recent years, China's new energy vehicles have achieved rapid development in the short term under the encouragement of a series of subsidy-type policies, such as financial subsidies and tax reductions. However, excessive fiscal and tax subsidies have exacerbated the subsidy dependence of NEVs and even triggered a large number of claims of compensation fraud and may face fairness disputes in international trade [2,3]. To this end, China began to implement a "subsidy retreat" plan for NEVs in 2016. Because the commercial competitive advantage of NEVs has not been fully formed, this recession of subsidies is very likely to bring the promotion and use of China's NEVs into a dark hour [4]. Therefore, effectively play a positive role of the nonsubsidized mechanisms in the promotion of NEVs consumption is a practical issue that deserves attention after the implementation of China's NEVs subsidy retreat plan.

The key to whether NEVs can obtain a commercial competitive advantage lies in whether NEVs can induce demand in potential consumers. Consumer demand is based in 
both material and spiritual motivations. Under the implementation of the NEVs subsidy retreat plan, it is necessary for NEVs to stimulate consumer desire to purchase on both the material and spiritual levels through nonsubsidized promotion mechanisms. It is necessary to change from subsidized policies designed to satisfy consumers' "sense of acquisition in purchase" to nonsubsidized policies designed to satisfy consumers' "sense of acquisition in use". Existing research is controversial about the sensitivity on the purchase intentions of potential consumers of NEVs. Gass et al. [5] found that the price concessions of NEVs are an important aspect that affects the sensitivity of consumers' purchase intentions, and it is more effective than stimulating consumers' purchase motivation by reducing costs. Oliver et al. [6] proposed that social influence and high-quality word-of-mouth activities have important impact to consumers' attitudes towards NEVs. Caperello et al. [7] believe that cultivating consumers' environmental awareness is an important factor that effectively stimulates consumers' purchasing motivation. Andrenacci et al. [8] found that charging infrastructure can effectively improve the charging convenience of NEVs and has a strong sensitivity to consumers' purchase intention.

In view of this, based on the subsidy decline for China's NEVs, this research analyzes the composition of the nonsubsidized consumption promotion mechanisms and the difference of its impact on potential consumers. First, the nonsubsidized consumption promotion mechanisms for NEVs are classified into two types: "concept induction" and "policy incentives". These two types are compared, and the difference in the sensitivity on the purchase intentions of potential consumers of NEVs is analyzed. Then, the cities where potential consumers live are divided into two types, medium to high and low; the education level of potential consumers is also divided into medium to high and low. Next, the differences in the sensitivity of the nonsubsidized consumption promotion mechanism to potential consumers with different education levels and in different cities are analyzed.

Compared with the existing literature, the possible marginal contribution of this research comprises three main points. (1) This study analyzes the role of the nonsubsidized consumption promotion mechanism in the promotion of NEVs and compensates for the shortcomings of existing literature that has mainly focused on subsidized policies for NEVs. (2) According to the basic understanding that consumer demand is based on both material and spiritual motivations, this research proposes an analytical framework for the nonsubsidized consumption promotion mechanism consisting of concept induction and policy incentives, which provides a reference for further research on and analyses of the nonsubsidized consumption promotion mechanism of NEVs. (3) Based on the two classifications of urban differences and consumer education levels, this paper analyzes the difference in the sensitivity of the nonsubsidized consumption promotion mechanism to potential consumers of NEVs and provides reference evidence for adopting differentiated marketing strategies according to local conditions and vary with each individual.

\section{Literature Review and Theoretical Analysis}

\subsection{Existing Research and Shortcomings}

The theoretical research on the purchase intentions of potential consumers of NEVs is mainly focused on three aspects.

The first aspect concerns the impact of NEV product attributes on consumer purchase intentions. Scholars have found that factors such as the price, environmental protection capabilities, use cost, and charging convenience of NEVs have an impact on consumer purchase intentions. For example, Potoglou and Kanaroglou [9] pointed out that a reduction in the price of NEVs and an improvement in environmental performance can effectively promote the purchase of NEVs by consumers. Helveston et al. [10] through a survey of Chinese and American consumers, found that consumers in both countries prefer NEVs that have lower prices and subsequent use costs, shorter acceleration times, and faster charging processes. Li et al. [11] stated that the price of NEVs and their use costs significantly affect consumer utility and that further reducing the price of NEVs and their use costs is an effective way to stimulate demand for NEVs. Hoen and Koetse [12] pointed out 
that increasing maximum driving distance, reducing charging time and improving the convenience of charging are conducive to stimulating consumer purchase intentions.

The second aspect concerns the impact of the individual heterogeneity of NEV consumers on purchase intentions. Scholars have found that consumer education, age, environmental awareness, social circle and other factors have an impact on purchase intentions. For example, Carley et al. [13] believed that the higher the education level of consumers is, the higher the market acceptance of NEVs is. Knez et al. [14] found that older consumers have a higher probability of buying NEVs, the main reasons for that they are more concerned with issues related to carbon dioxide and other emissions, and they are also attentive about vehicle noise. Kahn [15] reported that consumers' environmental awareness was in direct proportion to their preference for buying NEVs. Axsen and Kurani [16] found that consumers with a stronger sense of social responsibility, environmental awareness and willingness to support national development are more likely to choose NEVs. Sun et al. [17] pointed out that the proportion of relatives and friends who have purchased NEVs can significantly enhance consumer willingness to buy electric vehicles.

The third aspect concerns the impact of policies for the NEV industry on consumer purchase intentions. Scholars have found that policies such as NEV purchase subsidies, environmental protection regulations, and right-of-way privileges have an impact on consumer purchase intentions. For example, Lane and Potter's [18] research shows that government environmental regulations, oil price policies, and purchase subsidies significantly affect the purchase of NEVs. Hardman et al. [19] stated that government subsidies can stimulate consumer willingness to purchase NEVs to a certain extent. Larsson et al. [20] found that the purchase tax reduction policy is an important policy tool to promote the development of the NEV industry and stimulate the increase in sales of the NEV market. Irani et al. [21] evaluated the incentive effect of fiscal and taxation policies and found that such policies effectively stimulate consumers' purchase motivation, which is an important reason for many consumers to purchase NEVs. Bigerna et al. [22] pointed out that the most common policy instruments used to accelerate NEVs' developments are constituted by vehicle purchase subsidy and infrastructural investments, and compared with subsidies for alternative fuel vehicles, fuel price taxation have a more significant effect on consumers. Ma et al. [23] found that the policy granting right-of-way privileges has a significant positive impact on the popularization of NEVs and can effectively promote consumer purchase intentions.

The existing literature has laid a good foundation for our analysis of the impact of the nonsubsidized consumption promotion mechanisms of NEVs by potential consumers, but there are two shortcomings. First, the existing literature mainly studies the impact of subsidized policies such as government subsidies and tax incentives for NEVs on consumer purchase intentions, while research on nonsubsidized consumption promotion mechanisms is relatively rare. Second, there are few studies concerning the composition and classification of the nonsubsidized consumption promotion mechanism for NEVs. Although a few scholars have conducted analyses of nonsubsidized policy incentives such as the construction of charging stations and the double-points policy (the Parallel Administrative Measures for Passenger Vehicle Corporate Average Fuel Consumption Credits and New Energy Vehicle Credits, the essence is to form a market mechanism that promotes the coordinated development of energy-saving and NEVs by establishing a point trading mechanism) [24,25], the literature has seldom focused on nonsubsidized incentives such as concept induction, and it lacks a systematic analytical framework for nonsubsidized consumption promotion mechanisms.

\subsection{Theoretical Analysis and Research Hypothesis}

2.2.1. The Composition and Function of the Nonsubsidized Consumption Promotion Mechanisms for NEVs

Consumers have needs on two levels: material and spiritual. The motivation for consumption comes from psychological impulses caused by demand being stimulated at the material and spiritual levels, which further promote consumer behavior [26]. 
From the perspective of consumers' spiritual needs, a large number of studies have shown that consumer behavior is directly controlled and regulated by consumer concepts, and environmental awareness has an important influence on the green behavior of consumers [27]. Even if green products have a price premium, consumers with strong levels of environmental awareness will still choose to buy them [28]. A study on the promotion and application of NEVs in North America shows that the purchase behavior of most consumers displays wealth and strong environmental awareness. Some consumers will also buy hybrid vehicles without any subsidies [29,30]. At the same time, consumers will eliminate their own uncertainty about emerging technology products by learning from the attitudes and experiences of others through interpersonal interactions, thereby forming their own attitudes and behavioral decisions [31]. Therefore, stimulating potential consumers' motivation to purchase goods through concept induction is an important nonsubsidized mechanism in the promotion of NEV consumption.

Considering consumers' material needs, convenience of use, cruising range and supporting construction have become important factors affecting consumer adoption of NEVs [32]. NEVs have priority rights protection in licensing and on the road, giving NEVs the convenience of a right-of-way privileges over traditional vehicles, which has significantly increased consumer willingness to buy NEVs [33]. In addition, charging stations are important pieces of infrastructure that ensure the convenience of NEVs and help consumers avoid the inconvenience of finding gas stations for traditional-fuel vehicles; charging stations are also an important factor affecting consumer willingness to purchase NEVs [17]. Clearly, direct subsidy policies are not the only way to increase consumers sense of material gain. Through non-subsidy policies that improve the convenience of NEVs, consumers can also have a sense of material acquisition.

Based on the above theoretical analysis, this study proposes that the nonsubsidized consumption promotion mechanism for NEVs is composed of two parts: concept induction that affects consumers on the spiritual level and policy incentives that affect consumers on the material level. Concept induction for NEVs satisfies the spiritual needs of consumers. It is mainly carried out through instilling pro-environmental and pro-social perspectives in consumers to reflect consumers' positive personal image and sense of social responsibility. The pro-environmental perspective includes having a basic understanding of the ecological environment, advocating for environmental protection, engaging in green consumption, and pursuing the harmonious development of the ecological environment and human society. This perspective should lead consumers to pay attention to the green and environmental properties of NEVs and should promote green consumption behavior [9]. The pro-social perspective means that consumers tend to obtain information or opinions from social and interpersonal activities to evaluate and select goods [34]. Consumers consider a particular option only when sufficiently familiar with it. A consumer's willingness to consider a vehicle type increases through direct exposure to the different platforms, marketing, media attention, and word of mouth [35]. Consumers are extremely cautious about whether they should purchase NEVs, which are an emerging technology product. Participating in social activities and consulting other opinions can help eliminate consumer uncertainty and allow them to form a positive attitude towards NEVs [36]. However, promotion through the use of concept induction is not sufficient to stimulate consumer purchase intentions [37]. Although consumers tend to choose cars with environmentally friendly attributes or consider buying NEVs through the recommendations of others, the price, mileage and charging convenience of NEVs are still the main factors affecting consumer purchases [38]. Therefore, relying only on concept induction to encourage potential consumers to purchase NEVs would be somewhat weak; concept induction needs to be supplemented with policy incentives to solve the actual concerns of consumers and to stimulate consumer desire to buy at the material level.

The policy incentives of NEVs help to meet the material needs of consumers, mainly through granting right-of-way privileges and improving the charging infrastructure, which gives consumers the convenience of NEVs for personal use and a sense of gain at the 
material level, thereby stimulating consumption behavior. The "right-of-way privileges" policy implements differentiated traffic management for NEVs, gives preferential treatment to NEV owners for license plates and ignoring traffic restrictions, improves the convenience of driving NEVs, and promotes private demand [39]. The charging guarantee policy reduces the time costs of charging for users by increasing the construction of charging facilities, which can alleviate consumer anxiety about the mileage and battery life of NEVs and increase the purchase intentions of potential consumers [40]. Both types of policies stimulate consumer enthusiasm by providing consumers with a use environment that improves the convenience of NEVs for consumers. However, the implementation of the right-of-way privileges policy has had problems with unclear implementation rules and regional differences. There have been different incentives for urban consumers with different traffic pressures, and the fairness and legitimacy of the policy have been doubted. The implementation period for the construction of the charging infrastructure required by the charging guarantee policy is long, the investment is substantial, and the effect on consumer demand is delayed.

\subsubsection{The Heterogeneity in the Impact of the Nonsubsidized Consumption Promotion} Mechanisms for NEVs

China has adopted measures such as license restrictions and traffic restrictions to intervene in the allocation of road resources based on the traffic conditions in different cities. However, right-of-way privileges are given to NEVs, and the positive incentives to purchase NEVs in some cities with limited license plates and strict driving limits are very significant [41]. In addition, NEVs are emerging technologies and green products, and consumer education is closely related to one's environmental awareness and social network [42,43]. Differences in education levels will lead to significant differences in perceptions of and attitudes toward different policies. Therefore, it is necessary to analyze the heterogeneity that influences the nonsubsidized consumption promotion mechanism because of differences in city traffic patterns and consumer education.

(1) Differences in the impact of the nonsubsidized consumption promotion mechanism on consumers in different cities of residence

With the rapid increase in the population and the number of vehicles, the traffic in Chinese cities has gradually increased, and problems such as environmental pollution and traffic congestion have become increasingly serious [44]. To use road resources rationally and scientifically and to minimize traffic congestion and other problems, the Chinese government has adopted differentiated right-of-way policies based on the actual conditions in different cities, including license restriction, driving restriction or non-restriction, and owners of NEVs enjoy the right to receive priority licensing and driving privileges. The granting of right-of-way privileges has greatly reduced the marginal personal cost of purchasing NEVs and has improved the utility levels of consumers. Judging from the implementation of this policy in Beijing, Shanghai, Shenzhen, Guangzhou and other cities, the implementation of the policy granting right-of-way privileges is conducive to enhancing consumer enthusiasm for purchasing NEVs [45]. For cities with medium to high traffic pressure, right-of-way privileges can improve the convenience of consumer travel. This sense of convenience can increase consumer demand and transform consumer desire to buy NEVs into actual purchasing behavior. Charging infrastructure is an important part of the NEV consumption environment, and its effective supply is the basic prerequisite for the consumption and use of NEVs [46]. The charging guarantee policy for NEVs improves the basic conditions for NEV consumption by encouraging the accelerated construction and rational layout of charging infrastructure, thereby improving the basic conditions for NEV consumption and effectively reducing the private costs incurred by NEV consumers. These changes relax the constraints on NEV consumption and increase consumer willingness to buy NEVs [47]. For cities with low traffic pressure, the degree of road resource tension is relatively low, and consumers pay more attention to the convenience brought about by the charging guarantee policy. Therefore, we expect the impact of the nonsubsidized 
consumption promotion mechanism of NEVs on cities with different traffic patterns to be different.

(2) Differences in the impact of the nonsubsidized consumption promotion mechanism on consumers of different education levels

Consumers' individual characteristics are important factors influencing their adoption of NEVs. The individual factors that affect the market acceptance of NEVs mainly include demographic characteristics such as education level and personality characteristics such as environmental protection awareness and herd psychology [48]. Education level has a subtle influence on people's consumption perspectives and has a profound effect on consumers' material and intellectual consumption needs. Carley et al. [13] conducted a survey on the market acceptance of plug-in hybrid electric vehicles in the United States and found that consumers with higher academic qualifications have higher market acceptance of electric vehicles than do consumers with lower academic qualifications. Studies have shown that consumers with a high level of education have higher intellectual and cultural consumption needs, their environmental awareness levels are relatively higher, and they are more susceptible to conceptual influences. On the other hand, consumers with a low education level have a higher demand for material consumption and pay more attention to substantive welfare benefits [49]. Therefore, the nonsubsidized consumption promotion mechanism of NEVs are expected to have different effects on consumers with different education levels.

Based on the above theoretical analysis, the following research hypotheses are proposed, and the conceptual model of this research is shown in Figure 1.

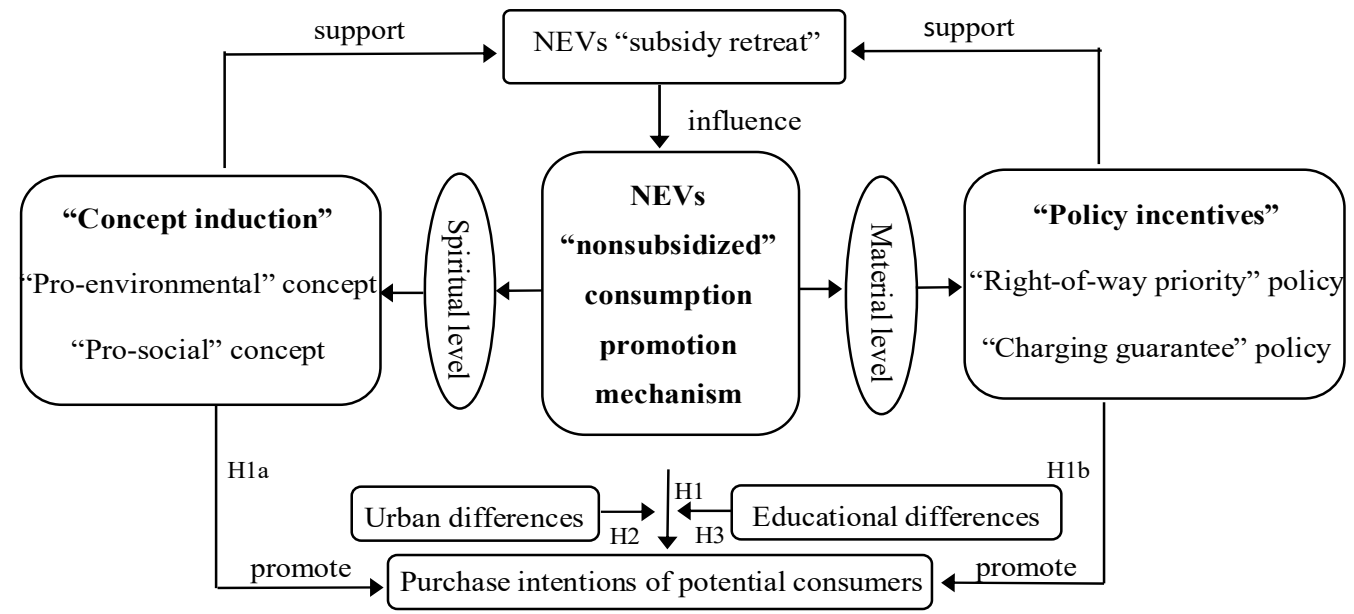

Figure 1. Conceptual model diagram.

Hypothesis 1: The nonsubsidized consumption promotion mechanism for NEVs has a positive impact on the purchase intentions of potential consumers.

Hypothesis 1a: Concept induction has a positive effect on the purchase intentions of potential consumers.

Hypothesis 1b: Policy incentives have a positive impact on the purchase intentions of potential consumers.

Hypothesis 1c: There are differences in the sensitivity of concept induction and policy incentives on the purchase intentions of potential consumers.

Hypothesis 2: The sensitivity of the nonsubsidized consumption promotion mechanism for NEVs on the purchase intentions of potential consumers varies across cities. 
Hypothesis 2a: For cities with medium to high traffic pressure, policy incentives are more sensitive than concept induction, and the right-of-way privileges policy is more sensitive than the charging guarantee policy.

Hypothesis 2b: For cities with low traffic pressure, the sensitivity of policy incentives is higher than that of concept induction, and the sensitivity of the charging guarantee policy is higher than that of the right-of-way privileges policy.

Hypothesis 3: There are differences in the sensitivity of the NEV nonsubsidized consumption promotion mechanism on the purchase intentions of potential consumers with different educational backgrounds.

Hypothesis 3a: For consumers with a medium to high level of education, concept induction is more sensitive.

Hypothesis 3b: For consumers with a low level of education, policy incentives are more sensitive.

\section{Methods}

\subsection{Questionnaire Design and Validity}

\subsubsection{Questionnaire Design}

Given that it is impossible to obtain data on the impact of the NEV nonsubsidized consumption promotion mechanism on potential consumers from a statistical database, this study uses a questionnaire to collect data. The measurement of the pro-environmental perspective is based on the scales of Dunlap et al. [50] and Schultz et al. [51]. The measurement of the pro-social perspective is based on the "social value" item in the PERVAL scale developed by Sweeney and Soutar [52] and the scales of Park and Lessig [53]. The measurement of the right-of-way privileges and charging guarantee incentive policies are based on Keeney's [54] scale. The measurement of purchase intention is based on the scales of Venkatesh et al. [55]. A questionnaire was formed on the basis of these scales, combined with the characteristics of NEV and the implementation of China's NEV policies. The measurement items use the Likert 5-level scale method. The questionnaire was improved on the basis of a small-scale presurvey, and the final measurement items are shown in Table 1. Respondents completed the questionnaire after being informed of the implementation of the subsidy retreat for NEVs.

\subsubsection{The Reliability and Validity of the Questionnaire}

Principal component analysis is used to perform factor analysis on concept induction and policy incentives. The results show that the cumulative explanatory power of proenvironment and pro-social perspectives for concept induction is $75.693 \%$ and that the standard load of each variable is greater than 0.5 , indicating that it is reasonable to divide concept induction into the pro-environment perspective and pro-social perspective. The cumulative explanatory power of right-of-way privileges and charging guarantee for policy incentives is $70.128 \%$, and the standard load for each is also greater than 0.5 , indicating that it is reasonable to divide the policy incentives into right-of-way privileges and charging guarantee incentives.

Before the relationship between variables was tested, the reliability and validity of the scale were tested. The results are shown in Table 2. The overall Cronbach's $\alpha$ value for the scale is 0.773 , which is greater than 0.7 . The factor loading for each item is between 0.552 and 0.751 ; all of which are greater than 0.5 and less than 0.95 . The coefficients of each latent variable are greater than 0.7 . These results indicate that the scale has high reliability. The $\mathrm{KMO}$ value is 0.792 , and the Barlett sphere test is significant (Chi-Square $=973.287$, $\mathrm{df}=15$, $p=0.000)$, indicating that the measurement items have high internal consistency and the research data validity is good. 
Table 1. Questionnaire measurement items.

\begin{tabular}{|c|c|c|c|c|}
\hline Latent Variables & $\begin{array}{l}\text { Measurement } \\
\text { Variable Name }\end{array}$ & & Measurement Items & References \\
\hline \multirow[t]{2}{*}{ Concept induction } & Pro-environmental & $\begin{array}{l}(1) \\
(2) \\
(3) \\
(4)\end{array}$ & $\begin{array}{l}\text { I tend to buy green and environmentally } \\
\text { friendly products. } \\
\text { I am willing to pay higher prices to reduce } \\
\text { environmental pollution. } \\
\text { I will buy NEVs because of their } \\
\text { environmental protection properties. } \\
\text { Using NEVs will help improve the } \\
\text { ecological environment. }\end{array}$ & $\begin{array}{l}\text { Dunlap et al. [50] } \\
\text { Schultz et al. [51] }\end{array}$ \\
\hline & Pro-social & $\begin{array}{l}(1) \\
(2) \\
(3) \\
(4)\end{array}$ & $\begin{array}{l}\text { Using NEVs can show my personality and } \\
\text { sense of fashion. } \\
\text { Using NEVs can reflect a positive personal } \\
\text { image and social responsibility. } \\
\text { If many people buy NEVs, then I will also } \\
\text { choose to buy. } \\
\text { If an individual who is highly influential in } \\
\text { my life recommends that I buy an NEV, I } \\
\text { will consider buying it. }\end{array}$ & $\begin{array}{l}\text { Sweeney and Soutar } \\
\text { [52], } \\
\text { Park and Lessig [53] }\end{array}$ \\
\hline \multirow[t]{2}{*}{ Policy incentives } & $\begin{array}{l}\text { Right-of-way } \\
\text { privilege }\end{array}$ & $\begin{array}{l}(1) \\
(2) \\
\text { (3) }\end{array}$ & $\begin{array}{l}\text { Priority driving and unlimited traffic } \\
\text { privileges encourage me to buy NEVs. } \\
\text { Priority registration and no license fee } \\
\text { encourage me to buy NEVs. } \\
\text { Exemptions from parking fees and bridge } \\
\text { tolls will encourage me to buy NEVs. }\end{array}$ & Keeney [54] \\
\hline & Charging guarantee & (3) & $\begin{array}{l}\text { The number of charging stations and the } \\
\text { convenience of charging are important } \\
\text { factors that affect my decision to purchase } \\
\text { NEVs. } \\
\text { The price of charging stations is an } \\
\text { important factor affecting my decision to } \\
\text { purchase NEVs. } \\
\text { Charging time is an important factor } \\
\text { affecting my decision to purchase NEVs. }\end{array}$ & Keeney [54] \\
\hline \multicolumn{2}{|c|}{ Purchase intention } & $\begin{array}{l}(1) \\
(2)\end{array}$ & $\begin{array}{l}\text { I am willing to buy NEVs. } \\
\text { When I buy a car next time, I will give } \\
\text { priority to NEVs. }\end{array}$ & Venkatesh [55] \\
\hline
\end{tabular}

Table 2. Results of the reliability and validity tests of the data.

\begin{tabular}{|c|c|c|c|c|c|}
\hline Latent Variables & Measurement Dimension & $\begin{array}{l}\text { Measurement } \\
\text { Items }\end{array}$ & $\begin{array}{c}\text { Factor Loading } \\
\text { Coefficient }\end{array}$ & Cronbach' $\alpha$ & KMO \\
\hline \multirow{7}{*}{ Concept induction } & \multirow{4}{*}{$\begin{array}{l}\text { Pro-environmental } \\
\text { perspective }\end{array}$} & EI1 & 0.594 & \multirow{5}{*}{0.728} & \multirow{5}{*}{0.749} \\
\hline & & EI2 & 0.604 & & \\
\hline & & EI3 & 0.707 & & \\
\hline & & EI4 & 0.718 & & \\
\hline & \multirow{4}{*}{ Pro-social perspective } & SI1 & 0.638 & & \\
\hline & & SI2 & 0.662 & \multirow{3}{*}{0.730} & \multirow{3}{*}{0.758} \\
\hline & & SI3 & 0.625 & & \\
\hline \multirow{6}{*}{ Policy incentives } & & $\begin{array}{l}\text { SI4 } \\
\text { PR1 }\end{array}$ & 0.664 & & \\
\hline & \multirow{3}{*}{$\begin{array}{l}\text { Right-of-way privilege } \\
\text { incentive }\end{array}$} & PR1 & 0.695 & \multirow{3}{*}{0.781} & \multirow{3}{*}{0.706} \\
\hline & & PR2 & 0.694 & & \\
\hline & & PR3 & 0.725 & & \\
\hline & Charging guarantee & CG1 & 0.731 & \multirow{2}{*}{0.789} & \multirow{2}{*}{0.762} \\
\hline & incentive & CG2 & $\begin{array}{l}0.552 \\
0.751\end{array}$ & & \\
\hline \multirow{2}{*}{\multicolumn{2}{|c|}{ Purchase intention }} & PI1 & 0.753 & \multirow{2}{*}{0.785} & \multirow{2}{*}{0.756} \\
\hline & & PI2 & 0.779 & & \\
\hline
\end{tabular}




\subsection{Sample Structure and Representativeness}

Since 2009, China has established the first batch of 25 NEV pilot promotion cities, and thereafter, the number of pilot promotion cities has increased to 88 . Considering that the first batch of $25 \mathrm{NEV}$ pilot promotion cities in China have gone through the whole process of China's NEV industry policy implementation, the data is complete and has typical representative significance. Therefore, this research selects "limited licensing and restricted traffic" and "non-restricted" sample cities from the first 25 pilot cities of NEVs in China. Taking into account the practical operability, the research samples of "cities with limited licensing and restricted traffic" in this study mainly come from Beijing, Shanghai, Guangzhou, Hangzhou and other cities, and the research samples of "nonrestricted cities "mainly come from Changsha, Chongqing, Hefei, etc. Beijing, Shanghai, Guangzhou and Hangzhou respectively represent several typical types of "restricted licensing" or "restricted traffic" modes adopted in China. Although Changsha, Chongqing and Hefei have not yet implemented strict "restricted licensing" or "restricted traffic" measures, relying on their regional NEV-related industries and manufacturing advantages, they have become typical of the development of NEVs in China that are nonrestricted cities. These cities also represent typical samples of the development of the NEVs market in different geographic regions of China.

In this study, a total of 950 questionnaires were issued, and 856 valid questionnaires were recovered. The sample structure is shown in Table 3. Among the valid samples, there are 409 survey respondents from cities with restrictive policies on licensing or traffic of fuel vehicles, and there are 447 respondents from cities with nonrestrictive policies, accounting for $47.78 \%$ and $52.22 \%$ of the sample, respectively. There are 405 males and 451 females, accounting for $47.31 \%$ and $52.69 \%$, respectively. Respondents aged $18 \sim 45$ years account for $95.79 \%$ of the sample, the 499 respondents with bachelor's degrees or above account for $58.30 \%$, and the monthly income level with the most respondents was the 3000 10,000 yuan range. An analysis of NEV consumer groups shows that the current consumers are mainly 20-40 years old, have a bachelor's degree or above, and are in the middle to high income levels [56]. Therefore, the survey samples for this study are highly consistent with the characteristics of potential consumers of NEVs, and the survey samples are representative.

Table 3. Sample structure.

\begin{tabular}{cccc}
\hline Item & Content & Number of Respondents & Percentage \\
\hline \multirow{2}{*}{ Gender } & Male & 405 & 47.31 \\
& Female & 451 & 52.69 \\
Age & 18-25 years old & 254 & 29.67 \\
& $26-36$ years old & 395 & 46.14 \\
& 36-45 years old & 171 & 19.98 \\
& $46-55$ years old & 25 & 2.92 \\
& Above 56 years old & 11 & 1.29 \\
Education level & High school and below & 203 & 23.71 \\
& Junior college & 154 & 17.99 \\
& Undergraduate & 429 & 50.12 \\
& Graduate and above & 70 & 8.18 \\
& Below 3000 yuan & 140 & 16.36 \\
Monthly income level & 3000-5000 yuan & 241 & 28.15 \\
& 5000-8000 yuan & 240 & 28.04 \\
& 8000-10,000 yuan & 173 & 20.21 \\
& Above 10,000 yuan & 62 & 7.24 \\
& Cities with limited & 409 & 47.78 \\
& licensing and restricted & & \\
& traffic & 447 & 52.22 \\
\hline
\end{tabular}




\subsection{Model Method and Variable Description}

\subsubsection{Model Method}

Considering that concept induction and the policy incentives in this study are both unobservable latent variables, we use a structural equation model, which is an analysis method used to test the relationship between observed variables and latent variables as well as between multiple latent variables. It is used to conduct path analysis for each variable relationship. Therefore, this study uses a structural equation model (SEM) to test the sensitivity of the purchase intention of potential consumers of NEVs to concept induction and policy incentives.

Since the full model contains six latent variables and 16 explicit variables, the relationships among the variables are complicated, and the analysis results may be unstable when the sample size is limited. To that end, this study combines the measurement items for the different dimensions in concept induction and policy incentives into question item groups, sums the question item groups for each dimension and averages them. The average value obtained is used as the new observation value to reduce any estimation error that may be caused by the small sample size. Based on the descriptions of related variables in Table 4, the structural equation and measurement equation for the SEM can be obtained as follows:

$$
\begin{gathered}
Y=\gamma_{1} \alpha_{1}+\gamma_{2} \alpha_{2}+\varepsilon_{1} \\
X_{i}=\lambda_{i} \alpha_{j}+\xi_{i}(i=1,2,3,4 ; j=1,2)
\end{gathered}
$$

\begin{tabular}{|c|c|c|c|c|}
\hline Variable Type & \multicolumn{2}{|c|}{ Variable Meaning } & Variable Name & Variable Value \\
\hline Explained variable & \multicolumn{2}{|c|}{ Purchase intentions for NEVs } & $Y$ & 1 (Very unwilling)-5 (Very willing) \\
\hline \multirow{3}{*}{ Explanatory variable } & Concept induction $\left(\alpha_{1}\right)$ & $\begin{array}{c}\text { Pro-environmental } \\
\text { Pro-social }\end{array}$ & $\begin{array}{l}X_{1} \\
X_{2}\end{array}$ & $\begin{array}{l}1 \text { (Very unwilling) }-5 \text { (Very willing) } \\
1 \text { (Very unwilling) }-5 \text { (Very willing) }\end{array}$ \\
\hline & \multirow{2}{*}{ Policy incentives $\left(\alpha_{2}\right)$} & Right-of-way privileges & $X_{3}$ & 1 (Very unwilling) -5 (Very willing) \\
\hline & & Charging guarantee & $Y^{\sigma}$ & 1 (Very unwilling) -5 (Very willing) \\
\hline
\end{tabular}

Table 4. Variable description.

Formula (1) is the structural equation, where $Y$ is consumer purchase intentions for NEVs; $\alpha_{1}$ and $\alpha_{2}$ represent concept induction and policy incentives, respectively; $\gamma_{1}$ and $\gamma_{2}$ are the corresponding path coefficients; and $\varepsilon_{1}$ is the error term of the structural equation. Formula (2) is the measurement equation for concept induction and the policy incentives", where $X_{i}$ is the observed variable capturing latent variable $i, \lambda_{i}$ represents the path coefficient, and $\zeta_{i}$ represents the error term of the corresponding measurement equation.

\subsubsection{Variable Description}

Explained variable: Following the research of Wang et al. [57], "purchase intentions for NEVs" is used as the explained variable, and the Likert five-point scale is used to measure the intensity of consumer purchase intentions.

Explanatory variables: Following the research of Jansson et al. [58] and Wang et al., [59] we take concept induction (pro-environmental and pro-social) and policy incentives (rightof-way privileges and the charging guarantee) as the explanatory variables and use the Likert five-point scale to measure the sensitivity of the two types of nonsubsidized consumption promotion mechanisms on consumer purchase intentions for NEVs.

\section{Results and Discussion}

\subsection{Sensitivity Analysis of Impact (I): Urban Differences}

\subsubsection{Model Path Analysis Results}

SEM was used to test the relationships among concept induction, policy incentives and purchase intentions. The model path analysis results for the two types of cities based on traffic load pressure-medium to high (cities with limited licensing and restricted traffic) (Figure 2) and low (nonrestricted cities) (Figure 3)—are shown in Table 5. 


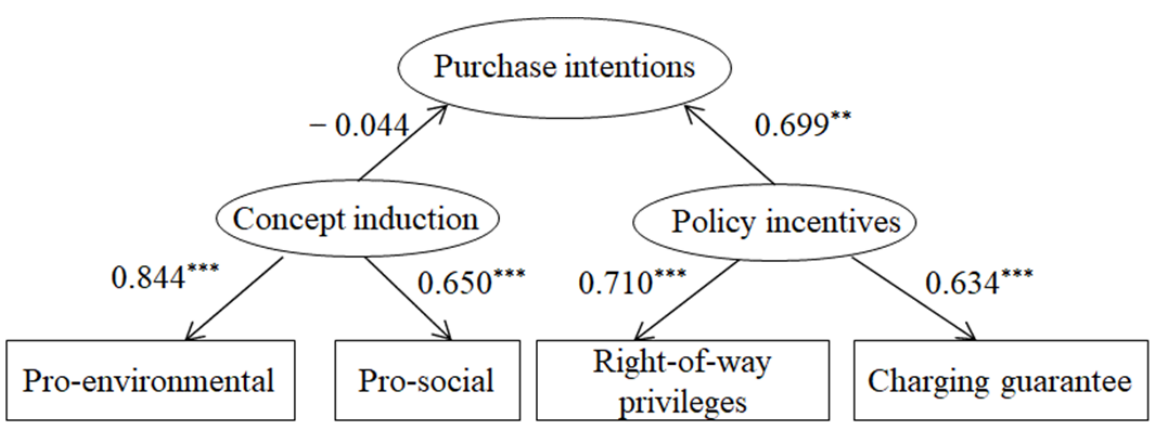

Figure 2. Model path analysis results. Cities with medium to high traffic pressure. Note: ${ }^{* *}$ represents $p<0.05,{ }^{* * *}$ represents $p<0.01$.

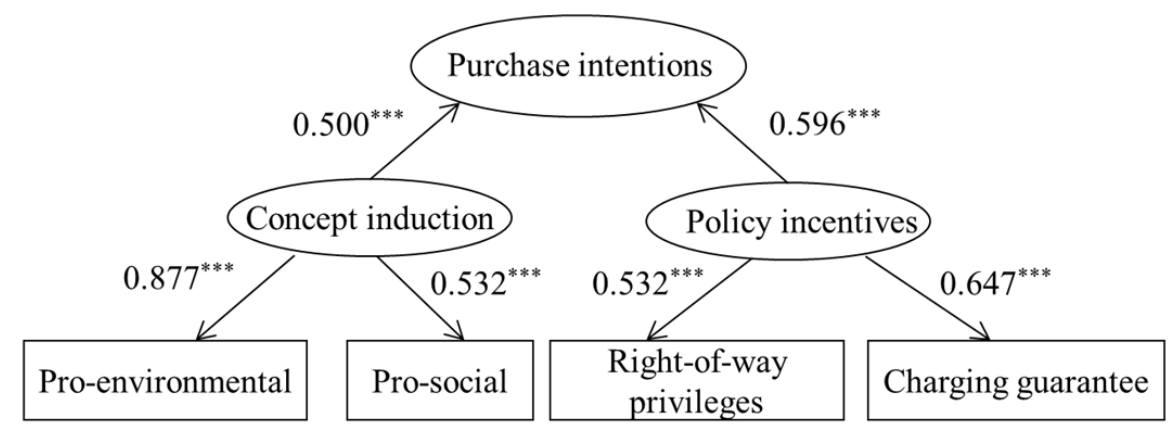

Figure 3. Model path analysis results. Cities with low traffic pressure. Note: ${ }^{* *}$ represents $p<0.01$.

Table 5. Model path analysis results.

\begin{tabular}{|c|c|c|c|c|c|}
\hline City Category & Path & Path Coefficient & City Category & Path & Path Coefficient \\
\hline \multirow{8}{*}{$\begin{array}{l}\text { Cities with } \\
\text { medium to high } \\
\text { traffic pressure } \\
\text { (limited licensing } \\
\text { and restricted } \\
\text { traffic) }\end{array}$} & Concept induction & & & Concept induction & \\
\hline & $\begin{array}{l}\rightarrow \text { Purchase } \\
\text { intentions }\end{array}$ & -0.044 & & $\begin{array}{l}\rightarrow \text { Purchase } \\
\text { intentions }\end{array}$ & $0.500 * * *$ \\
\hline & Policy incentives & & & Policy incentives & \\
\hline & $\begin{array}{l}\rightarrow \text { Purchase } \\
\text { intentions }\end{array}$ & $0.699 * *$ & & $\begin{array}{l}\rightarrow \text { Purchase } \\
\text { intentions }\end{array}$ & $0.596^{* * *}$ \\
\hline & $\begin{array}{l}\text { Pro-environmental } \\
\rightarrow \text { Concept } \\
\text { induction }\end{array}$ & $0.844^{* * *}$ & $\begin{array}{l}\text { Cities with low } \\
\text { traffic pressure }\end{array}$ & $\begin{array}{c}\text { Pro-environmental } \\
\rightarrow \text { Concept } \\
\text { induction } \\
\text { Pro-social }\end{array}$ & $0.877^{* * *}$ \\
\hline & $\begin{array}{l}\text { Pro-social } \\
\rightarrow \text { Concept } \\
\text { induction }\end{array}$ & $0.650 * * *$ & (nonrestricted) & $\begin{array}{l}\text { Pro-social } \\
\rightarrow \text { Concept } \\
\text { induction }\end{array}$ & $0.532 * * *$ \\
\hline & $\begin{array}{l}\text { Right-of-way } \\
\text { privileges } \\
\rightarrow \text { Policy } \\
\text { incentives }\end{array}$ & $0.710^{* * *}$ & & $\begin{array}{l}\text { Right-of-way } \\
\text { privileges } \\
\rightarrow \text { Policy } \\
\text { incentives }\end{array}$ & $0.532^{* * *}$ \\
\hline & $\begin{array}{l}\text { Charging } \\
\text { guarantee } \\
\rightarrow \quad \text { Policy } \\
\text { incentives }\end{array}$ & $0.634^{* * *}$ & & $\begin{array}{l}\text { Charging } \\
\text { guarantee } \\
\rightarrow \quad \text { Policy } \\
\text { incentives }\end{array}$ & $0.647^{* * *}$ \\
\hline
\end{tabular}

Note: ${ }^{* *}$ represents $p<0.05,{ }^{* * *}$ represents $p<0.01$

\subsubsection{Reliability and Validity Test Results}

The overall Cronbach's $\alpha$ values for the two scales in the cities with medium to high and low traffic pressure are 0.819 and 0.728 , respectively, indicating that the reliability of the data used in the two studies is good. The factor loading for the two items is between $0.591 \sim 0.820$ and $0.565 \sim 0.751$, respectively, which are both greater than 0.5 and less than 0.95 . The coefficients of each latent variable are greater than 0.7 , indicating that the two scales 
have high reliability. The KMO values are 0.832 and 0.725 , respectively, and the Barlett sphere test is significant (Chi-Square $=633.209, \mathrm{df}=15, p=0.000$; Chi-Square $=416.140$, $\mathrm{df}=15, p=0.000$ ), indicating that the data have high internal consistency and good validity. At the same time, the square root of the AVE of each latent variable is greater than the correlation coefficient between the latent variables, indicating that the scale has good discriminative validity.

The goodness-of-fit indices are summarized in Table 6. The actual value of each index in the table exceeds (or in the case of RMR and RMSEA, is below) the critical value, indicating that the theoretical model fits the observed data well.

Table 6. Goodness-of-fit indices of the model.

\begin{tabular}{ccccccccc}
\hline Fit Index & GFI & AGFI & RMR & RMSEA & NFI & IFI & TLI & CFI \\
\hline $\begin{array}{c}\text { Actual value of cities with } \\
\text { medium to high traffic pressure }\end{array}$ & 0.985 & 0.949 & 0.008 & 0.066 & 0.975 & 0.986 & 0.965 & 0.986 \\
$\begin{array}{c}\text { Actual value of cities with low } \\
\text { traffic pressure }\end{array}$ & 0.967 & 0.915 & 0.018 & 0.050 & 0.907 & 0.920 & 0.928 & 0.918 \\
$\quad>0.9$ & $>0.9$ & $<0.05$ & $<0.1$ & $>0.9$ & $>0.9$ & $>0.9$ & $>0.9$ \\
\hline
\end{tabular}

4.1.3. Main Results and Discussion

(1) In cities with medium to high traffic pressure, the sensitivity of policy incentives on consumer purchase intentions is significant, while the effect of concept induction is statistically insignificant. Of the policy incentives, both the right-of-way privileges and charging guarantee policies have high sensitivity for influencing consumer purchase intentions. The sensitivity of right-of-way privileges is relatively higher. The data in Table 5 show that the standardized path coefficient for "concept induction $\rightarrow$ purchase intentions" is -0.044 , which fails the significance test; the standardized path coefficient for "policy incentive $\rightarrow$ purchase intentions" is 0.699 , which is significant with $p<0.05$. This result shows that in cities with medium to high traffic pressure, only policy incentives have a clear effect on consumer purchase intentions. For the policy incentives, the coefficients of the right-of-way privileges and charging guarantee policies on the purchase intentions of potential consumers are 0.710 and 0.634 , respectively, which are both significant with $p<0.001$, indicating that the sensitivity of the right-of-way privileges policy is higher than that of the charging guarantee policy. For consumers in cities with medium to high traffic pressure, because they experience traffic congestion and travel difficulties, the right-of-way privileges and charging guarantee policies for NEVs can improve the driving experience and have a high incentive effect on consumer purchase intentions. Of the two policies, right-of-way privileges have a more obvious impact on consumer purchase intentions. Research hypothesis $\mathrm{H} 2 \mathrm{a}$ is supported.

(2) In cities with low traffic pressure, the sensitivity of both concept induction and policy incentives on consumer purchase intentions is very obvious. The sensitivity of policy incentives is relatively higher. For concept induction, the sensitivity of the pro-environmental perspective is higher than that of the pro-social perspective. For policy incentives, the sensitivity of the charging guarantee policy is higher than that of the right-of-way privileges policy. The data in Table 5 show that the standardized path coefficient for "concept induction $\rightarrow$ purchase intentions" is 0.500 , and the standardized path coefficient for "policy incentive $\rightarrow$ purchase intentions" is 0.596 ; both of which are significant with $p<0.001$. This result shows that in cities with low traffic pressure, concept induction and policy incentives are both key driving factors behind consumers making NEV purchase decisions. The factor loads for the two components of concept induction are both greater than 0.5 , and the factor load for the pro-environmental perspective is greater than that for the pro-social perspective. The coefficients of the two factors on concept induction are 0.877 and 0.532 , respectively, and both of which are significant. The coefficients of the right-of-way 
privileges incentive and the charging guarantee incentive on potential consumer purchase intentions are 0.532 and 0.647 , respectively, and both of which are significant with $p<0.001$. The sensitivity of the charging guarantee policy is significantly higher than that of the right-of-way privileges policy. For consumers in cities with low traffic pressure, because the traffic pressure is relatively small, the driving advantages brought about by the NEV right-of-way privileges policy are less attractive to consumers, and consumers are more concerned about whether the charging problem of NEVs can be solved to ensure the normal use of NEVs. Additionally, the factors in concept induction have an impact on consumer purchase intentions, and the effect of pro-environmental concept induction is higher than that of pro-social. Research hypothesis $\mathrm{H} 2 \mathrm{~b}$ is supported.

(3) The sensitivity of the nonsubsidized consumption promotion mechanism of NEVs on potential consumers varies across cities. The impact of policy incentives in cities with medium to high traffic pressure is higher than that in cities with low traffic pressure. The sensitivity of concept induction in cities with medium to high traffic pressure is lower than that in cities with low traffic pressure. The data in Table 5 show that the standardized path coefficient for "policy incentive $\rightarrow$ purchase intentions" in cities with medium to high traffic pressure is 0.699 , which is significant with $p<0.05$, and the standardized path coefficient for "concept induction $\rightarrow$ purchase intentions" is -0.044 , which fails the significance test. The standardized path coefficient for "policy incentive $\rightarrow$ purchase intentions" in cities with low traffic pressure is 0.596 , and the standardized path coefficient for "concept induction $\rightarrow$ purchase intentions" is 0.500 ; both of which are significant with $p<0.001$. These results show that the sensitivity of consumers in cities with medium to high traffic pressure to policy incentives is higher than that of consumers in cities with low traffic pressure, while sensitivity to concept induction is lower than in cities with low traffic load pressure. Cities with medium to high traffic pressure experience more severe road congestion than cities with low traffic pressure do. Policy incentives can effectively solve travel difficulties and licensing anxiety experienced by consumers, and such incentives have a relatively higher effect on consumers in this type of city. However, the sensitivity of concept induction in cities with medium to high traffic pressure is statistically insignificant and is lower than that in cities with low traffic pressure. Research hypothesis H2 is proven.

\subsection{Sensitivity Analysis of Impact (II): Difference in Education Level}

\subsubsection{Model Path Analysis Results}

SEM is used to test the relationships among concept induction, policy incentives and purchase intentions. Table 7 shows the model path analysis results for the two types of consumers based on education levels: medium to high (college or above) (Figure 4) and low (high school or below) (Figure 5).

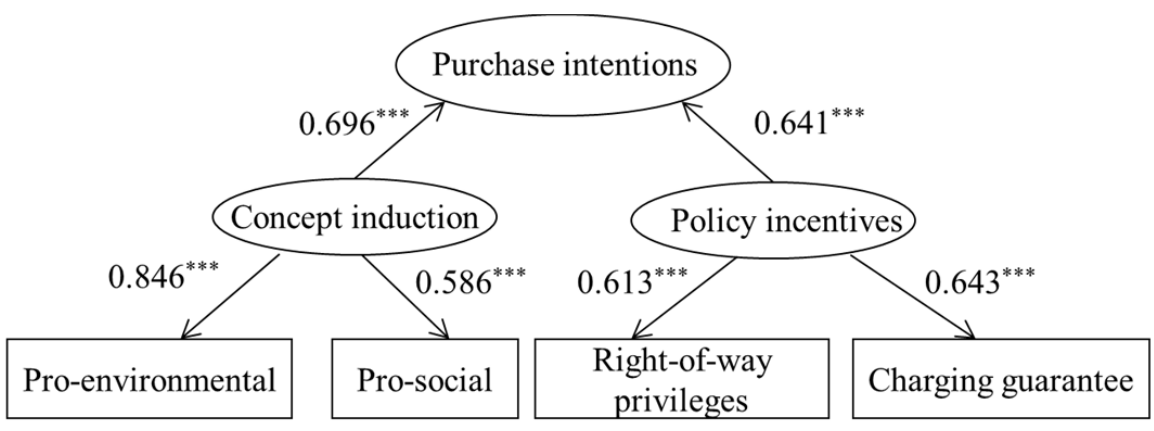

Figure 4. Model path analysis results. Consumers with medium to high education. Note *** represents $p<0.01$. 
Table 7. Model path analysis results.

\begin{tabular}{|c|c|c|c|c|c|}
\hline $\begin{array}{l}\text { Consumer } \\
\text { Category }\end{array}$ & Path & Path Coefficient & $\begin{array}{l}\text { Consumer } \\
\text { Category }\end{array}$ & Path & Path Coefficient \\
\hline \multirow{8}{*}{$\begin{array}{l}\text { Consumers with } \\
\text { medium to high } \\
\text { education (college } \\
\text { degree or above) }\end{array}$} & Concept induction & & \multirow{8}{*}{$\begin{array}{l}\text { Consumers with } \\
\text { low education } \\
\text { (high school or } \\
\text { below) }\end{array}$} & Concept induction & \\
\hline & $\begin{array}{l}\rightarrow \text { Purchase } \\
\text { intentions }\end{array}$ & $0.696^{* * *}$ & & $\begin{array}{l}\rightarrow \text { Purchase } \\
\text { intentions }\end{array}$ & $0.576^{* * *}$ \\
\hline & Policy incentives & & & Policy incentives & \\
\hline & $\begin{array}{c}\rightarrow \text { Purchase } \\
\text { intentions }\end{array}$ & $0.641^{* * *}$ & & $\begin{array}{c}\rightarrow \text { Purchase } \\
\text { intentions }\end{array}$ & $0.639^{* * *}$ \\
\hline & $\begin{array}{c}\text { Pro-environmental } \\
\rightarrow \text { Concept } \\
\text { induction } \\
\text { Pro-social }\end{array}$ & $0.846^{* * *}$ & & $\begin{array}{c}\text { Pro-environmental } \\
\rightarrow \text { Concept } \\
\text { induction } \\
\text { Pro-social }\end{array}$ & $0.693^{* * *}$ \\
\hline & $\begin{array}{l}\rightarrow \text { Concept } \\
\text { induction }\end{array}$ & $0.586^{* * *}$ & & $\begin{array}{l}\rightarrow \text { Concept } \\
\text { induction }\end{array}$ & $0.840^{* * * *}$ \\
\hline & $\begin{array}{l}\text { Right-of-way } \\
\text { privileges } \\
\rightarrow \text { Policy } \\
\text { incentives }\end{array}$ & $0.613^{* * *}$ & & $\begin{array}{l}\text { Right-of-way } \\
\text { privileges } \\
\rightarrow \text { Policy } \\
\text { incentives }\end{array}$ & $0.313^{* * *}$ \\
\hline & $\begin{array}{l}\text { Charging } \\
\text { guarantee } \\
\rightarrow \quad \text { Policy } \\
\text { incentives }\end{array}$ & $0.643^{* * *}$ & & $\begin{array}{l}\text { Charging } \\
\text { guarantee } \\
\rightarrow \quad \text { Policy } \\
\text { incentives }\end{array}$ & $0.742^{* * *}$ \\
\hline
\end{tabular}

Note: ${ }^{* * *}$ represents $p<0.01$.

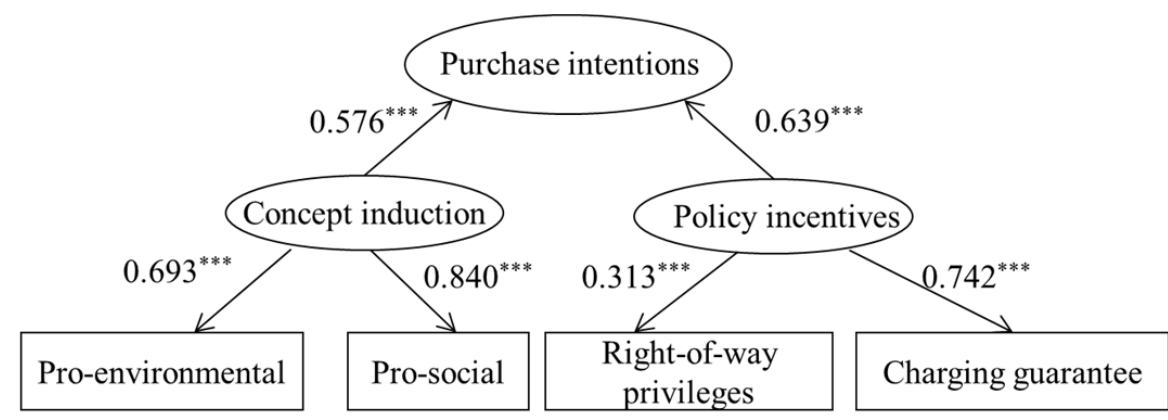

Figure 5. Model path analysis results. Consumers with low education. Note: ${ }^{* * *}$ represents $p<0.01$.

\subsubsection{Reliability and Validity Test Results}

The overall Cronbach's $\alpha$ values of the two scales for medium to high and low education levels are 0.779 and 0.824 , respectively, indicating that the data used are reliable. The factor loadings for the two items are between $0.544 \sim 0.783$ and $0.582 \sim 0.809$, respectively, which are both greater than 0.5 and less than 0.95 . The coefficient of each latent variable is greater than 0.7 , indicating that the two scales have high reliability. The KMO values are 0.789 and 0.742, respectively, and the Barlett sphere test is significant (Chi-Square $=880.787$, $\mathrm{df}=15, p=0.000$; Chi-Square $=567.731, \mathrm{df}=15, p=0.000)$, indicating that the data have high internal consistency and are valid. At the same time, the square root of the AVE of each latent variable is greater than the correlation coefficient between the latent variables, indicating that the scale has good discriminative validity.

The goodness-of-fit indices are summarized in Table 8. The actual value of each index in the table exceeds (or in the case of RMR and RMSEA, is below) the critical value, indicating that the theoretical model fits the observed data well. 
Table 8. Goodness-of-fit indices for the model.

\begin{tabular}{ccccccccc}
\hline Fitting Index & GFI & AGFI & RMR & RMSEA & NFI & IFI & TLI & CFI \\
\hline $\begin{array}{c}\text { Actual value of consumers with } \\
\text { medium to high education }\end{array}$ & 0.977 & 0.942 & 0.015 & 0.082 & 0.943 & 0.953 & 0.910 & 0.953 \\
$\begin{array}{c}\text { Actual value of consumers with } \\
\text { low education }\end{array}$ & 0.985 & 0.922 & 0.012 & 0.083 & 0.967 & 0.980 & 0.922 & 0.979 \\
$\quad \begin{array}{c}\text { Recommended value } \\
\text { Remmen }\end{array}$ & $>0.9$ & $>0.9$ & $<0.05$ & $<0.1$ & $>0.9$ & $>0.9$ & $>0.9$ & $>0.9$ \\
\hline
\end{tabular}

\subsubsection{Main Results and Discussion}

(1) For consumers with medium to high education, the sensitivity of both types of the nonsubsidized consumption promotion mechanisms on the potential consumers of NEVs is obvious, but the sensitivity of concept induction is higher than that of policy incentives. For concept induction, the sensitivity of the pro-environmental perspective is higher than that of the pro-social perspective. For the policy incentives, the sensitivity of the charging guarantee policy is higher than that of the right-of-way privileges policy. The data in Table 7 show that among consumers with a medium to high education level, the standardized path coefficient for "concept induction $\rightarrow$ purchase intentions" is 0.696 , and the standardized path coefficient for "policy incentive $\rightarrow$ purchase intentions" is 0.641 ; both of which are significant with $p<0.01$. For concept induction, the sensitivity coefficients of the pro-environmental and pro-social perspectives are 0.846 and 0.586 , respectively, and both of which are significant with $p<0.001$. For the policy incentives, the coefficients measuring the influence of the right-of-way privileges policy and the charging guarantee policy on the purchase intentions of potential consumers are 0.613 and 0.643 , respectively, and both of which are significant; the sensitivity of the charging guarantee policy is relatively higher than that of the right-of-way privileges policy. These results show that both concept induction and policy incentives are significantly sensitivity for consumers with medium to high education, but the sensitivity coefficient of concept induction is greater than that of the policy incentives. It can be seen that consumers with a high level of education are more advanced in their thinking and perspectives, they have a higher demand for intellectual and cultural consumption, and pursue the abundance of the spiritual world, so their sensitivity to concept induction is relatively higher than to policy incentives. The sensitivity of the pro-environmental perspective is higher than that of the pro-social perspective. Consumers with a medium to high education level learn more about environmental protection and ecological pollution-related concepts, and their environmental awareness is relatively high. The largest feature of NEVs is their ability to protect the environment, reduce energy consumption and reduce ecological pollution. There is a close connection between awareness of environmental protection issues and the consumption and use of NEVs, so the pro-environmental perspective plays a significant role in promoting the purchase intention of consumers with medium to high education levels. Research hypothesis H3a is supported.

(2) For consumers with low education, the two types of the nonsubsidized consumption promotion mechanism have significant sensitivity on potential consumers of NEVs, but the sensitivity of policy incentives is higher than that of concept induction. For concept induction, the sensitivity of the pro-social perspective is higher than that of the pro-environmental perspective. For policy incentives, the sensitivity of the charging guarantee policy is higher than that of the right-of-way privileges policy. The data in Table 7 show that the standardized path coefficient for "concept induction $\rightarrow$ purchase intentions" is 0.576 , and the standardized path coefficient for "policy incentive $\rightarrow$ purchase intentions" is 0.639 ; both of which are significant with $p<0.01$. For concept induction, the sensitivity coefficients of the pro-environmental and prosocial perspectives are 0.693 and 0.840 , respectively, which are both significant with $p<0.001$, and the sensitivity of pro-social perspectives is higher than that of proenvironmental perspectives. For the policy incentives, the coefficients measuring 
the influence of the right-of-way privileges policy and the charging guarantee policy on the purchase intentions of potential consumers are 0.613 and 0.643 , respectively; both of which are significant. The sensitivity of the charging guarantee policy is relatively higher than that of the right-of-way privileges policy. These result shows that both concept induction and policy incentives significantly increase the purchase intentions of consumers with low education, but the sensitivity of policy incentives is relatively higher. Because consumers with a low education level are relatively lagging consumption concept and have a higher demand for material consumption, they are more concerned about policy benefits they can actually enjoy. Therefore, the sensitivity of policy incentives is higher than that of concept induction for such consumers. As a typical emerging-technology product, NEVs are relatively weakly accepted by consumers with low levels of education, and they are more inclined to rely on the opinions and behaviors of others in social interactions to form attitudes towards the consumption and use of NEVs than those with more education. Therefore, sensitivity to the pro-social perspective is relatively higher for this type of consumer. Research hypothesis H3b is supported.

(3) The sensitivity of the nonsubsidized mechanism to promote the consumption of NEVs to potential consumers differs with the consumer educational background. Regardless of concept induction or policy incentives, the sensitivity of consumers with medium to high education is higher than that of consumers with low education. The data in Table 7 show that the standardized path coefficient for "concept induction $\rightarrow$ purchase intentions" for consumers with medium to high education is 0.696 , and the standardized path coefficient for "policy incentive $\rightarrow$ purchase intentions" is 0.641 ; both of which are significant with $p<0.01$. The standardized path coefficient for "concept induction $\rightarrow$ purchase intentions" is 0.576 , and the standardized path coefficient for "policy incentive $\rightarrow$ purchase intentions" is 0.639 ; both of which are significant with $p<0.01$. The results show that the sensitivity of consumers with medium to high education to concept induction and policy incentives is higher than that of consumers with low education. Consumers with a medium to high education level update their concept quickly, and they pay relatively high attention to and understand the policy documents issued by the state and are clearer about the welfare support provided by the policy. The perspectives of consumers with low education are relatively behind, and these consumers generally have a low level of understanding of NEV policies or have inaccurate ideas about the policies. Research hypothesis H3 is supported.

In summary, apart from in cities with medium to high traffic pressure, concept induction has a positive impact on the purchase intentions of potential consumers. Research hypothesis H1a is supported in some cases. Policy incentives have a positive impact on the purchase intentions of potential consumers. Research hypothesis H1b is supported. There is a difference in the sensitivity of concept induction and policy incentives on the purchase intentions of potential consumers, and research hypothesis H1c is supported. Research hypothesis $\mathrm{H} 1$ is supported in some cases.

\section{Conclusions and Policy Implications}

\subsection{Research Implications}

With the decline in China's NEVs subsidies as a backdrop, this study analyzes the composition of the nonsubsidized consumption promotion mechanism of NEVs and the difference in the impact of the mechanisms on potential consumers. The results of the study found that the nonsubsidized consumption promotion mechanisms have an impact on consumer purchase intentions. However, there are differences in the impacts on consumers with different education levels and in cities with different traffic patterns. Consumers in cities with medium to high traffic pressure are more sensitive to the right-of-way privileges component of the policy incentives, and consumers in cities with low traffic pressure are more sensitive to the charging guarantee component of the policy incentives. Consumers 
with medium to high education are more sensitive to the pro-environmental component of concept induction, and consumers with low education are more sensitive to the charging guarantee component of the policy incentives.

To further promote the sustainable development of the NEV consumption market, China should take the role of the nonsubsidized consumption promotion mechanisms in the implementation of the NEV subsidy retreat plan seriously. Specifically:

(1) At the level of urban differences, cities with medium to high traffic pressure, due to traffic pressure and the strict implementation of the restricted-licenses and restrictedtraffic measures, the right-of-way priority policy in the nonsubsidized consumption promotion mechanism should be the primary means. It is necessary to fully develop the convenience of NEVs, continue to protect the priority driving rights of NEVs and highlight the unique attributes and advantages of NEVs in the regional market. At the same time, cities with low traffic load pressure, not only need to rely on policy incentives at material level, but also need to be assisted by concept induction. Only by complementing each other can these mechanisms promote the development of the NEV market to the greatest extent possible. Therefore, the implementation of nonsubsidized policies should be strengthened, and relevant policy documents should be issued to induce consumers to understand and desire to use NEVs at the conceptual level. It is necessary to increase investments in the construction of the charging infrastructure to provide a good environment and reasonable guarantee of charging availability for consumers of NEVs.

(2) At the level of consumer differences, for consumers with a medium to high education level, it is important to focus on the role of concept induction in promoting the consumption of NEVs and cultivate potential consumers' pro-environmental and pro-social concepts. In particular, it is necessary to strengthen consumers' proenvironmental perspectives, hold more environmental protection activities and increasingly promote the advantages of NEVs for environmental protection. For consumers with low education, it is necessary to emphasize the incentive effects at the policy level. While intensifying the implementation of the NEV right-of-way privileges policy, attention should also be paid to the construction and optimal layout of infrastructure, such as charging stations for NEVs, to solve the fundamental concerns of consumers. At the same time, the government and related organizations can hold more informational events about NEVs. Such organizations can also cultivate the opinions of social leaders and enable them to actively disseminate information about NEVs and their own positive attitudes towards NEVs. In this way, consumers can learn about the attributes and policy advantages of NEVs from a wide range of social relationships, thereby eliminating uncertainty in the use of NEVs and enhancing consumer willingness to purchase.

(3) It is necessary to further focus on the goal of promoting the sustainable development of NEVs, combined with the background of the gradual declining of industry subsidies, promoting the diversification of NEVs subsidized and nonsubsidized consumption promotion mechanisms. On the one hand, change the form of direct consumer subsidy policies to overcome the excessive policy dependence and lack of incentives caused by direct consumption subsidies. On the other hand, further enrich the content of nonsubsidized consumption promotion mechanisms. Combining the market conditions of NEVs in different cities and the social and economic characteristics of consumers and guide the target consumer groups to increase their willingness to purchase and use NEVs in a targeted manner. Make great efforts to promote the formation of a popular and large-scale market and achieve an effective transition and complementary advantages between subsidized and nonsubsidized consumption promotion mechanisms.

(4) Compared with the subsidy policy, the non-subsidy policy is more oriented towards the NEVs industry and all consumers. From the perspective of non-monetary policy support, it is possible to avoid to a certain extent the equity concerns caused 
by the government's "picking of winners" and excessive intervention through subsidy policies. The implementation of the nonsubsidized mechanisms for NEVs in China should adopt differentiated strategies based on local conditions and vary with each individual. The same is true for countries other than China. One size fits all policy measures cannot be adopted, but corresponding incentive measures should be adopted according to national conditions and actual consumer characteristics. Organically combine subsidy policies and non-subsidy promotion mechanisms to promote the sustainable development of the NEVs industry and adjust the proportion of non-subsidy measures based on the facts.

\subsection{Research Limitations and Prospects}

Based on the current trend of subsidy decline, this research studies the sensitivity of the nonsubsidized consumption promotion mechanism of NEVs to the purchase intention of potential consumers from the perspectives of urban transportation resources and consumers' education level. However, the research still has the following limitations: (1) Due to the limited sample size of this study, we did not further classify consumers based on the classification of cities, further analysis of consumers with different education levels in cities with different traffic load pressures may bring new research findings. (2) How education level may relate to income levels and thus impact on the difference between the groups regarding the nonsubsidized consumption promotion mechanism. These are our further research directions in the future.

Author Contributions: Conceptualization, Y.X.; investigation, Y.L.; methodology, Y.L.; writingoriginal draft preparation, Y.L.; writing — review and editing, Y.X. and J.W.; funding acquisition, J.W. All authors have read and agreed to the published version of the manuscript.

Funding: This research was funded by Hunan Provincial Natural Science Foundation Youth Project (No. 2019JJ50144) and Hunan Provincial Transportation Science and Technology Project (No. 201845).

Institutional Review Board Statement: Not applicable.

Informed Consent Statement: Informed consent was obtained from all subjects involved in the study.

Data Availability Statement: Data sharing not applicable.

Acknowledgments: The authors express their most sincere gratitude to all respondents who participated in this study.

Conflicts of Interest: The authors declare no conflict of interest.

\section{References}

1. Guo, Z.W.; Li, T.; Peng, S.T.; Zhang, H.C. Environmental and economic consequences of the incentive policy on electric vehicle industry: A CGE based study in China. Resour. Conserv. Recycl. 2021, 169, 105542. [CrossRef]

2. Zhang, X.; Bai, X. Incentive policies from 2006 to 2016 and new energy vehicle adoption in 2010-2020 in China. Renew. Sustain. Energy Rev. 2017, 70, 24-43. [CrossRef]

3. Yang, D.X.; Qiu, L.S.; Yan, J.J.; Chen, Z.Y.; Jiang, M.X. The government regulation and market behavior of the new energy automotive industry. J. Clean. Prod. 2019, 210, 1281-1288. [CrossRef]

4. Wang, N.; Pan, H.Z.; Zheng, W.H. Assessment of the incentives on electric vehicle promotion in China. Transp. Res. Part A Policy Pract. 2017, 101, 177-189. [CrossRef]

5. Gass, V.; Schmidt, J.; Schmid, E. Analysis of alternative policy instruments to promote electric vehicles in Austria. Renew. Energy 2014, 61, 96-101. [CrossRef]

6. Oliver, J.D.; Rosen, D.E. Applying the Environmental Propensity Framework: A Segmented Approach to Hybrid Electric Vehicle Marketing Strategies. J. Mark. Theory Pract. 2010, 18, 377-393. [CrossRef]

7. Caperello, N.D.; Kurani, K.S. Households' Stories of Their Encounters with a Plug-In Hybrid Electric Vehicle. Environ. Behav. 2012, 44, 493-508. [CrossRef]

8. Andrenacci, N.; Ragona, R.; Valenti, G. A demand-side approach to the optimal deployment of electric vehicle charging stations in metropolitan areas. Appl. Energy 2016, 182, 39-46. [CrossRef]

9. Potoglou, D.; Kanaroglou, P.S. Household demand and willingness to pay for clean vehicles. Transp. Res. Part D Transp. Environ. 2007, 12, 264-274. [CrossRef] 
10. Helveston, J.P.; Liu, Y.; Feit, E.M.; Fuchs, E.; Klampfl, E.; Michalek, J.J. Will subsidies drive electric vehicle adoption? Measuring consumer preferences in the U.S. and China. Transp. Res. Part A Policy Pract. 2015, 73, 96-112. [CrossRef]

11. Li, G.D.; Luo, R.Q.; Gu, Y.F. Government promotion policy and new energy vehicle demand: Evidence from Shanghai. China Ind. Econ. 2019, 42-61. [CrossRef]

12. Hoen, A.; Koetse, M.J. A choice experiment on alternative fuel vehicle preferences of private car owners in the Netherlands. Transp. Res. Part A Policy Pract. 2014, 61, 199-215. [CrossRef]

13. Carley, S.; Krause, R.M.; Lane, B.W.; Graham, J.D. Intent to purchase a plug-in electric vehicle: A survey of early impressions in large US cites. Transp. Res. Part D Transp. Environ. 2013, 18, 39-45. [CrossRef]

14. Knez, M.; Jereb, B.; Obrecht, M. Factors influencing the purchasing decisions of low emission cars: A study of Slovenia. Transp. Res. Part D Transp. Environ. 2014, 30, 53-61. [CrossRef]

15. Kahn, M.E. Do greens drive Hummers or hybrids? Environmental ideology as a determinant of consumer choice. 2007, 54, 129-145. [CrossRef]

16. Axsen, J.; Kurani, K.S. Hybrid, plug-in hybrid, or electric-What do car buyers want? Energy Policy 2013, 61, 532-543. [CrossRef]

17. Sun, X.H.; Sun, R.; Xu, S. Network effects of electric vehicle industry: Identification and heterogeneity test. China Soft Sci. 2018, 4 , 132-145.

18. Ben, L.; Potter, S. The adoption of cleaner vehicles in the UK: Exploring the consumer attitude-action gap. J. Clean. Prod. 2007, 15, 1085-1092. [CrossRef]

19. Hardman, S.; Chandan, A.; Tal, G.; Turrentine, T. The effectiveness of financial purchase incentives for battery electric vehicles-A review of the evidence. Renew. Sustain. Energy Rev. 2017, 80, 1100-1111. [CrossRef]

20. Larsson, M.; Gronkvist, S.; Alvfors, P. Upgraded biogas for transport in Sweden-Effects of policy instruments on production, infrastructure deployment and vehicle sales. J. Clean. Prod. 2016, 112, 3774-3784. [CrossRef]

21. Irani, A.; Chalak, A. Harnessing motorists' potential demand for hybrid-electric vehicles in Lebanon: Policy options, $\mathrm{CO}_{2}$ emissions reduction and welfare gains. Transp. Policy 2015, 42, 144-155. [CrossRef]

22. Bigerna, S.; Bollino, C.A.; Micheli, S.; Polinori, P. Revealed and stated preferences for $\mathrm{CO}_{2}$ emissions reduction: The missing link. Renew. Sustain. Energy Rev. 2017, 68, 1213-1221. [CrossRef]

23. Ma, S.C.; Fan, Y.; Feng, L.Y. An evaluation of government incentives for new energy vehicles in China focusing on vehicle purchasing restrictions. Energy Policy 2017, 110, 609-618. [CrossRef]

24. Zhou, Y.; Pu, Y.; Chen, S.; Fang, F. Government support and development of emerging industries-A new energy industry survey. Econ. Res. J. 2015, 50, 147-161.

25. Li, X.; Xiong, Y.Q. Characteristics of the impact of corporate average fuel consumption-new energy vehicle credits (CAFC-NEV) mandate on the new energy vehicle industry: From the perspective of business and environmental performances. Resour. Sci. 2021, 43, 1-11.

26. Wang, Z.Y.; Su, Y. Research on golf consumption motivation based on consumer self-concept. Psychol. Behav. Res. 2014, 12, 395-399.

27. Zhao, H.H.; Gao, Q.; Wu, Y.P.; Wang, Y.; Zhu, X.D. What affects green consumer behavior in China? A case study from Qingdao. J. Clean. Prod. 2014, 63, 143-151. [CrossRef]

28. De Medeiros, J.F.; Duarte Ribeiro, J.L.D.; Cortimiglia, M.N. Influence of perceived value on purchasing decisions of green products in Brazil. J. Clean. Prod. 2016, 158-169. [CrossRef]

29. Chandra, A.; Gulati, S.; Kandlikar, M. Green drivers or free riders? An analysis of tax rebates for hybrid vehicles. Soc. Sci. Electron. Publ. 2010, 60, 78-93. [CrossRef]

30. Beresteanu, A.; Li, S.J. Gasoline prices, government support, and the demand for hybrid vehicles in the united states. Int. Econ. Rev. 2011, 52, 161-182. [CrossRef]

31. Nordlund, A.; Jansson, J.; Westin, K. New Transportation Technology: Norm Activation Processes and the Intention to Switch to an Electric/Hybrid Vehicle. Transp. Res. Procedia 2016, 14, 2527-2536. [CrossRef]

32. Hidrue, M.K.; Parsons, G.R.; Kempton, W.; Gardner, M.P. Willingness to pay for electric vehicles and their attributes. Resour. Energy Econ. 2011, 33, 686-705. [CrossRef]

33. Xiong, Y.Q.; Li, X.L. The difference in the role of the new energy vehicle supply and demand policy in the heterogeneous market. Stud. Sci. Sci. 2019, 37, 597-606.

34. Wang, H.Y.; Xing, H.W.; Tian, H. Position the "Golden Quadrant" of Green Consumption: A Response Surface Analysis Based on the Stereotype Content Model. Nankai Bus. Rev. 2018, 21, 203-214.

35. Struben, J.; Sterman, J.D. Transition challenges for alternative fuel vehicle and transportation systems. Soc. Sci. Electron. Publ. 2008, 35, 1070-1097. [CrossRef]

36. Shoham, A.; Ruvio, A. Opinion leaders and followers: A replication and extension. Psychol. Mark. 2010, 25, 280-297. [CrossRef]

37. Florenlhal, B.; Grossman, P.Z. Barriers to adoption of hybrid cars in the Midwest:focusing on generation Y. J. Bus. Behav. Sci. 2009, 21, 64-79.

38. Gould, J.; Golob, T.F. Clean air forever? A longitudinal analysis of opinions about air pollution and electric vehicles. Transp. Res. Part D Transp. Environ. 1998, 3, 157-169. [CrossRef]

39. Diao, Q.; Sun, W.; Yuan, X.; Li, L.l.; Zheng, Z. Life-cycle private-cost-based competitiveness analysis of electric vehicles in China considering the intangible cost of traffic policies. Appl. Energy 2016, 567-578. [CrossRef] 
40. Santos, G.; Davies, H. Incentives for quick penetration of electric vehicles in five European countries: Perceptions from experts and stakeholders. Transp. Res. Part A Policy Pract. 2020, 137, 326-342. [CrossRef]

41. Zhang, G.Q.; Xu, Y.M. The international mirror and extension of the application of new energy vehicle policy tools. Reform 2017, 3, 130-138.

42. Wang, Q.Y.; Hou, P. Research on the environmental behavior willingness of Beijing urban residents. Chin. Popul. Resour. Environ. 2010, 20, 61-67.

43. Liu, G.; Wang, Z.Y.; Cheng, X.R. Advantages of "friends circle", inner group conditions and internet entrepreneurship-A new perspective based on the theory of integrated social identity and embeddedness. China Ind. Econ. 2016, 8, 110-126. [CrossRef]

44. Bilbao-Ubillos, J. The costs of urban congestion: Estimation of welfare losses arising from congestion on cross-town link roads. Transp. Res. Part A Policy Pract. 2008, 42, 1098-1108. [CrossRef]

45. Wang, N.; Tang, L.H.; Zhang, W.J.; Guo, J.H. How to face the challenges caused by the abolishment of subsidies for electric vehicles in China? Energy 2019, 166, 359-372. [CrossRef]

46. Ran, G.H.; Li, T. Re-examination of the impact of infrastructure investment on residents' consumption. Econ. Sci. 2017, 6, 45-57.

47. Yang, Z.H.; Wen, X.L.; Chen, L.N. Research on the relationship between government consumption and private consumption: Based on panel unit root test and panel cointegration analysis. World Econ. 2009, 32, 68-82.

48. Wang, N.; Yan, R.L.; Liu, Y.F. Study on identification of potential consumers of electric vehicles and market acceptance. China Soft Sci. 2015, 70-84.

49. Diniz, S.C.; Machado, A.F. Analysis of the consumption of artistic-cultural goods and services in Brazil. J. Cult. Econ. 2011, 35, 1-18. [CrossRef]

50. Dunlap, R.E.; Van Liere, K.D.; Mertig, A.G.; Jones, R.E. Measuring Endorsement of the New Ecological Paradigm: A Revised NEP Scale. J. Soc. Issues 2000, 56, 425-442. [CrossRef]

51. Schultz, P.W.; Gouveia, V.V.; Cameron, L.D.; Tankha, G.; Marek, F. Values and their Relationship to Environmental Concern and Conservation Behavior. J. Cross Cult. Psychol. 2005, 36, 457-475. [CrossRef]

52. Sweeney, J.C.; Soutar, G.N. Consumer perceived value: The development of a multiple item scale. J. Retail. 2001, 77, 203-220. [CrossRef]

53. Park, C.W.; Lessig, V.P. Students and Housewives: Differences in Susceptibility to Reference Group Influence. J. Consum. Res. 1977, 102-110. [CrossRef]

54. Keeney, R.L. The Value of Internet Commerce to the Customer. Manag. Sci. 2011, 45, 533-542. [CrossRef]

55. Venkatesh, V.; Morris, M.G.; Davis, G.B.; Davis, F.D. User acceptance of information technology: Toward a unified view. MIS Q 2003, 27, 425-478. [CrossRef]

56. Krupa, J.S.; Rizzo, D.M.; Eppstein, M.J.; Lanute, D.B.; Gaalema, D.E.; Lakkaraju, K.; Warrender, C.E. Analysis of a consumer survey on plug-in hybrid electric vehicles. Transp. Res. Part A Policy Pract. 2014, 64, 14-31. [CrossRef]

57. Wang, S.Y.; Fan, J.; Zhao, D.T.; Yang, S.; Fu, Y.G. Predicting consumers' intention to adopt hybrid electric vehicles: Using an extended version of the theory of planned behavior model. Transportation 2016, 43, 123-143. [CrossRef]

58. Jansson, J.; Nordlund, A.; Westin, K. Examining drivers of sustainable consumption: The influence of norms and opinion leadership on electric vehicle adoption in Sweden. J. Clean. Prod. 2017, 154, 176-187. [CrossRef]

59. Wang, S.Y.; Li, J.; Zhao, D.T. The impact of policy measures on consumer intention to adopt electric vehicles: Evidence from China. Transp. Res. Part A Policy Pract. 2017, 105, 14-26. [CrossRef] 